\title{
RELEASE STRATEGY OF Chrysoperla carnea (Stephens) USED AGAINST APHIDS IN AN IPM PERSPECTIVE
}

\author{
(Received: 31.8.2006)
}

\author{
By \\ S. A. El Arnaouty, H. M. A. Badawy, A. M. El Gantiry ${ }^{*}$ and N.M. Gaber" \\ Department of Economic Entomology and Pesticides Sciences, Faculty of Agriculture, \\ Cairo University, Giza, Egypt. \\ * Plant Protection Research Institute, Agriculture Research Center, Giza.
}

\begin{abstract}
The residual effect of the chosen pesticides; bancol 50\% WP, confidor 20\% SL, aphox 50\% DG, trebon $30 \%$ EC, vertimec 1.8\% EC and topas (100) 10\% EC on the second larval instar of Chrysoperla carnea and also on their developing stages were evaluated under laboratory and greenhouse conditions. The direct toxic effect of the tested pesticides on the second larval instar and the cumulative effect on the developed stages were compatible with time elapsed and successive stages. The same trend of toxicity and biological affects of the tested pesticides to the second larval instar of Ch. carnea and their developed stages in laboratory was also found in greenhouse. The toxicity results of pesticide residues against the second larval instar at initial time in greenhouse can be classified into three categories. The first category includes confidor and trebon which caused $30.0 \%$ mortality. The second category includes the insecticide aphox and the acaricide vertimec with $23.3 \%$ mortality. The third category includes bancol and the fungicide topas (100), which showed low toxicity to the second larval instar with 16.7 and $13.3 \%$ mortality. The results of total mortality for different stages at initial time of application indicated that aphox was the most toxic one, while topas (100) was the least toxic. The total percent mortality was mostly higher in the laboratory tests than those in greenhouse trials except in case of aphox and confidor. The residual lethal toxicity of chemical pesticides persisted for three days after application in greenhouse trials and four days in case of laboratory tests. Results show that the treated second larval instar with chosen pesticides induced adverse effects on the female's fecundity and egg hatching. Data indicated that the adverse effect on the fecundity of Ch. carnea females using the tested pesticides was shorter in greenhouse trials than those in laboratory tests. All pesticide treatments are affected the survival of $C h$. carnea hatching. The percent hatchability increased while the percent sterility decreased with time elapsed in all treatments of pesticides. Percent hatchability was increased from the range of $77-82 \%$ at initial time to $90-93 \%$ after four days of pesticides application. There were slightly differences in percent hatchability of eggs between pesticide treatments and control after three and four days post application. The residual effect of chosen pesticides; bancol, confidor, aphox, trebon, vertimec and topas (100) on the mortality of the different stages and female's fecundity of Ch. carnea indicating that four days waiting period is required after application of these pesticides to prevent any effect on the release stage $\left(2^{\text {nd }}\right.$ larval instar) and their developed stages.
\end{abstract}

Key words: Chrysoperla carnea, cumulative effect, release timing, safety period, toxicity of pesticides residue.

\section{1- INTRODUCTION}

Chrysoperla carnea (Stephens) (Neuroptera :Chrysopidae) appears to be a good candidate for use in (IPM) programs, where it is a voracious feeder (Balasubramani and Swamiappan, 1994), has a relatively broad range of acceptable preys (Hydron and WhiteComb, 1979), relative ease of mass production (Morrison, 1985), and tolerance to some groups of pesticides (Hassan et al., 1985, Bigler and Waldburger 1994, Chen and Liu 2002). Classical biological control (i.e. the introduction of a predator or parasite for the control of a particular pest species) and inundation control (i.e. repeated mass release of a control agent) programs impose high requirements on the selectivity of chemical control agents and also knowledge about the residual effect of the candidate chemicals on 
biological control agents to be combined within them.

Within most crop ecosystems, exist some pest insects that have no effective biological controls (Castane et al., 1996). The use of pesticides to manage these pests frequently devastates natural enemy complexes and in turn encourages pest resurgence or secondary pest flares (Grundy et al., 2000). The toxic effects of insecticide application occur through a continuum of events from direct exposure during application to contact with dry deposited residues (Croft 1990). However, it is often the residual effects of insecticides that cause mortality and physiological disorders to populations of biological enemies for considerable length of time (Bellows and Morse 1993, Bellows et al., 1993).

Integrated pest management (IPM) was developed as a consequence of the incompatibility of pesticides with biological control. IPM practice on different vegetable crop production in greenhouse recommends the preservation of beneficial insects for control of various insect pests. Emphasis on IPM is especially important in early season of vegetable crops, when biological enemies are capable of maintaining some pests below economic thresholds (Elzen 2001). Chemical insecticides sprays become necessary however, as the growing season progresses and numbers of pest insect's increase and plant fruiting structures become more susceptible to attack (Frisbie et al., 1989). Information on the toxicities of various pesticides used on vegetable crops in the greenhouse to the Ch. carnea is therefore important in selection of compounds that will minimize mortality of this predator.

Badawy et al., (2006) suggested that the bancol 50\% WP, confidor $20 \%$ SL, aphox $50 \%$ $\mathrm{DG}$, trebon $30 \% \mathrm{EC}$, vertimec $1.8 \% \mathrm{EC}$ and topas (100) $10 \% \mathrm{EC}$ are the less harmless pesticides for Ch. carnea and may be suitable for integration with Ch. carnea in IPM program. These pesticides were registered in Egypt for the use against leaf miners, thrips, aphids, whiteflies, red spider mites and powdery mildew disease on vegetable crops, respectively. The purpose of this study was to determine the residual toxicity and safety periods of these pesticides to the release stage (second larval instar) of Ch. carnea and their developed stages in the laboratory and greenhouse.

\subsection{Used pesticides \\ 2. MATERIAL AND METHODS}

The tested pesticides belong to three categories; insecticides, acaricides and fungicides.
They were selected on the basis of their commercially use in the control of different insects and diseases on vegetable crops and also due to their low toxicity to Ch. carnea as described by Badawy et al., (2006). The chosen pesticides in this study were bancol 50\% WP, confidor 20\% SL, aphox 50\% DG, trebon 30\% EC, vertimec $1.8 \%$ EC and topas (100) 10\% EC belong to the following groups; nereistoxin analogue, neonicotinoid, carbamate, non ester-pyrethroid, bio-pesticide and triazole, respectively. All tested pesticides were used at their recommended rate of application.

\subsection{Rearing of Ch. carnea}

Adults of Ch. carnea were placed in boxes (16 $\mathrm{cm} \times 24 \mathrm{~cm} \times 11 \mathrm{~cm}$ ) and covered with a black crepe sheet for oviposition. The droplets of semi artificial diet ( $4 \mathrm{~g}$ yeast hydrolyzed, $8 \mathrm{~g}$ honey and 4 $\mathrm{ml}$ distilled water) were provided for adults on wax paper. The boxes were changed three times weekly and the eggs were collected daily. The eggs of $C h$. carnea were placed in Plexiglas boxes $(60 \mathrm{~cm}$ long x $40 \mathrm{~cm}$ large). Ephestia kuehniella eggs were used as food source for larval rearing and dry sawdust was used as a substrate to avoid cannibalism. After pupation, the cocoons were placed immediately together for emergence. The adults were collected daily and 50 couples were placed in boxes. $C h$. carnea was reared in controlled rooms at $25 \pm 2^{\circ} \mathrm{C}$ and $65 \pm 5 \%$ of relative humidity. Aphids were reared on cucumber seedlings under standard conditions according to the method of El-Gantiry et al., (1999), while E. kuehniella was reared according to El-Arnaouty (2001).

The population of $C h$. carnea that is rearing since ten years in "Chrysopa mass rearing unit" Faculty of Agriculture, Cairo University was used as laboratory susceptible strain to candidate pesticides in this study.

\subsection{Evaluation of pesticide residues in laboratory}

Evaluation method of Weichel and Nauen (2003) was used to study the residual effect of tested pesticides on the second larval instar of $C h$. carnea and its developmental stages in the laboratory and greenhouse. Pepper seeds (Capiscum annuam, cv. Mazurka) were grown individually on peat moss sphagnum in plastic pots $(10 \times 10 \times 10 \mathrm{~cm})$. After one month, seedlings were transported into bigger plastic pots $(30 \times 30 \times 30$ $\mathrm{cm})$ and kept in the laboratory at $27 \pm 3^{\circ} \mathrm{C}$ and $65 \pm$ $5 \%$ of R.H. for another month. All tested pesticides were used as foliar sprays. Each pesticide was applied on ten pepper seedlings using a one liter hand sprayer. The recommended rates were 
sprayed and then pepper seedlings were left under laboratory conditions till complete dryness. Another ten pepper seedlings were sprayed with water and used as a check treatment. Five larvae of the second instar per each seedling were exposed to pesticide deposit on pepper leaves individually in clip leaf cage for 24 hours. Eggs of E. kuehniella were provided as food for the larvae in the inner wall of each clip leaf cage. Fifty larvae of $C h$. carnea were tested for each pesticide. After exposure, the larvae were transferred to clean vials and reared individually on E. kuehniella eggs. Treated and untreated larvae were observed daily to determine the mortality percentage until it reached the adult stage. The same method was done after one, two, three and four days of application to study the residual effect of the tested pesticides on the mortality of the second larval instar and their developed stages in laboratory. Mortality counts were recorded in each stage and corrected by Abbott's formula (1925).

About ten pairs from each treatment were reared individually in small boxes $(7 \mathrm{~cm}$ in diameter and $6 \mathrm{~cm}$ height) and covered with black fabric as egg laying support. The droplets of semi artificial diet (4g yeast hydrolyzed, $8 \mathrm{~g}$ honey and 4 $\mathrm{ml}$ distilled water) on wax paper and moist cotton wool were provided for the adults. The laid eggs were collected daily and fecundity was estimated as the total number of eggs per each female. Deterrent index was calculated according to Lundgren (1975) i.e. Deterrent index $=(B-A)$ 100/ $(\mathrm{A}+\mathrm{B})$, where $\mathrm{A}$ and $\mathrm{B}$ are the number of eggs laid in the treatment and control, respectively.

\subsection{Evaluation of pesticide residues in the greenhouse}

The same previously technique in laboratory study was also used to evaluate the residual effect of the tested pesticides in the greenhouse at $27 \pm$ $5^{\circ} \mathrm{C}, 65 \pm 5 \%$ of R.H. and a photoperiod of 15:9 (light : dark) in Faculty of Agriculture, Cairo University. With one exception cucumber seedlings were used instead of pepper seedlings. Larvae resulting from exposure to pesticide deposit on cucumber leaves were maintained reared to reach the adult stage to determine the different biological aspects. The percentage of sterility was calculated according to the equation of Tappozada et al., (1966).

$\%$ Sterility $=100-\{(\mathrm{a} \times \mathrm{b}) /(\mathrm{A} \times \mathrm{B})\} \mathrm{X} 100$

Where, $\mathrm{a}=$ Number of eggs laid/female in treatment. $\mathrm{b}=\%$ of hatchability in treatment. $\mathrm{A}=$ Number of eggs laid/female in control. $\mathrm{B}=\%$ of hatchability in control.
There was another trial in the greenhouse using the same method as described previously to study the residual effect of the tested pesticides on the second larval instar when fed on aphids instead of eggs of E. kuehniella at the third and fourth day of application only.

The data were statistically analyzed using proc ANOVA in SAS. Mean replicates were conducted using Dunce Multiple Range Test in SAS (SAS 1985).

\section{RESULTS}

\subsection{Residual effect of chosen pesticides on the} second larval instar (release stage) of $C h$. carnea and its developed stages in the laboratory.

The present study aimed to evaluate the residual effect of the chosen pesticides, which gave low efficacy against laboratory strain and field populations of Ch. carnea in our previous work (Badawy et al., 2006), in order to determine the release time of the second larval instar after application of these pesticides. The candidate pesticides were used at the recommended rates of application for spraying the pepper seedlings. Data show the direct effect of the tested pesticides on the second larval instar of Ch. carnea at initial, 1, 2, 3 and 4 days of spraying and also their biological effects on the developing stages of the treated second larval instar in the laboratory.

The toxicity results are set out in Tables (1-6). There is a relationship between mortality percentage and time elapsed for all pesticides. All candidate pesticides affected the survival of the second larval instar of Ch. carnea at the initial time. They can be classified into two groups according to their toxicity. Confidor, aphox, trebon and vertimec demonstrated the highest mortality percentages to the $2^{\text {nd }}$ larval instar of Ch. carnea with percent mortality ranged between 26.7 and $33.3 \%$. The second group, bancol and the fungicide topas (100) gave the lowest mortality percentage (20 and 16.7\%). The percentage mortality of the second larval instar at the initial time decreased to $0.0-3.3 \%$ in the fourth day of application.

The previous data of our working group (Badawy et al., 2006) indicate that bancol, confidor, aphox, trebon, vertimec and topas (100) were the safest available pesticides for the predator Ch. carnea at initial time, which caused percent mortalities to the second larval instar of laboratory culture reached $40,36,32,30,30$ and $16 \%$, respectively, using dry film method in small plastic cups. The corresponding values after exposure to treated pepper leaves were 20.0, 26.7, 33.3, 30.0, 
26.6 and $16.7 \%$, respectively. These results indicated that there were slightly differences in the toxicity of tested pesticides at the recommended rates by using two different evaluation methods with the exception of bancol and confidor.

The cumulative effect of candidate pesticides on mortality of developed stages produced from the treated second larval instar of Ch. carnea was evaluated. The third larval instar of Ch. carnea was more affected than pupae and adults. The percent mortality of the third larval instar ranged between 6.7 and $13.3 \%$ at the initial time and then gradually decreased to reach $0.0 \%$ in the fourth day of application. No cumulative effect for topas (100) and vertimec residues on the third larval instar was found in the $2^{\text {nd }}$ and $3^{\text {rd }}$ days post application. Slightly cumulative effect on Ch. carnea pupae was observed at the initial and first day with $3.3 \%$ mortality except in the case of vertimec, which gave $6.6 \%$ at the initial time of application. Also, residues of chosen pesticides caused low mortality against the developed adults in the first two days of application. However topas (100) 10\%EC did not produce any effect on the adults developed from the treated $2^{\text {nd }}$ larval instar through experimental period. Although the cumulative mortality in the developed stages at initial time was low but the total mortality was high and reached sometimes $50 \%$ in the case of aphox and trebon, due to increase in the mortality of treated second larval instar. The total percent mortality at initial time was 46.3, 40.0, 36.6 and $30 \%$ using vertimec, confidor, bancol and topas (100), respectively, then gradually decreased with time elapse and reached $3.3 \%$ in the fourth day post application for all the tested pesticides except trebon $(0.0 \%)$.

Treated second larval instar with the recommended rates of application for chosen pesticides induced adverse effect on the fecundity of Ch. carnea females. Data in Tables (1-6) showed that in treatments of confidor, trebon, vertimec and topas (100) the deposited eggs significantly decreased until the third day post application. On the other hand, the significant decrease reached the second day post application using bancol and aphox treatments. At the initial time, trebon highly reduced the number of eggs per female from 700 in control to 412 with deterrent index $25.9 \%$. Confidor, aphox, vertimec and topas (100) had intermediate activity and reduced egg number per female from $620,800,750$ and 760 in control treatments to $393,514,477$ and 500, respectively. The deterrent indices values of these treatments were 22.41, 21.77, 22.25 and $20.64 \%$, respectively. Bancol treatment was least effective in reducing the numbers of egg-laying with deterrent index $6.78 \%$ only. The deterrent indices decreased gradually with time elapse and reached $0.0,0.84,0.07,1.45,1.56$ and $1.45 \%$ at the fourth day post application using bancol, confidor, aphox, trebon, vertimec and topas (100), respectively. The residual effect of chosen pesticides; bancol, confidor, aphox, trebon, vertimec and topas (100) on the mortality of the different stages and female's fecundity of Ch. carnea indicated that four days waiting period is required after the application of these pesticides to prevent any effect on the release stage ( $2^{\text {nd }}$ larval instar) and their developed stages.

\subsection{Residual effect of chosen pesticides on the second larval instar (release stage) of $C h$. carnea and its developed stages in the greenhouse.}

The same tests that were conducted on pepper seedlings in the laboratory to study the residual effect of chosen pesticides on the second larval instar and their developed stages were also applied in greenhouse trials on cucumber seedlings. Also, the second larval instar (release stage) was fed on the eggs of Ephestia kuheniella. Although the cucumber seedlings were used in the greenhouse instead of pepper seedlings that were used in laboratory tests but the same toxicity trend of the tested pesticides to the second larval instar of Ch. carnea and their developed stages in laboratory was also found in the greenhouse.

The direct toxic effect of the tested pesticides on the second larval instar and the cumulative effect on the developed stages was compatible with time elapsed and successive stages. The toxicity results of pesticide residues against the second larval instar and their further stages of Ch. carnea are set out in Tables (7-12). They can be classified into three categories according to their toxicity against the second larval instar at initial time. The first category includes confidor and trebon which caused $30.0 \%$ mortality. The second category includes the insecticide aphox and the acaricide vertimec with $23.3 \%$ mortality. The third category includes bancol and the fungicide topas (100) which showed low toxicity to the second larval instar at initial time with 16.7 and $13.3 \%$ mortality. The percentage mortality of the second larval instar was gradually decreased from 16.7, 30.0, 23.3, 30.0, 23.3 and $13.3 \%$ at the initial time using bancol, confider, aphox, trebon, vertimec and topas (100), respectively, to $3.3 \%$ in the treatments of bancol, aphox, trebon and topas (100) and to $6.7 \%$ by confidor and vertimec at the third day post 
Table (1): Residual effect of bancol $50 \%$ WP on mortality $(\%)$ of the $2^{\text {nd }}$ larval instar and further $3^{\text {rd }}$ larval instar, pupae, adults and fecundity of Ch. carnea (Stephens) in the laboratory.

\begin{tabular}{|c|c|c|c|c|c|c|c|c|}
\hline \multirow{4}{*}{$\begin{array}{c}\text { Days } \\
\text { post application }\end{array}$} & \multirow{4}{*}{$\begin{array}{l}\text { Mortality (\%) of } \\
\text { the } 2^{\text {nd }} \text { larval } \\
\text { instar }\end{array}$} & \multicolumn{7}{|c|}{ Cumulative effect } \\
\hline & & \multicolumn{4}{|c|}{ Mortality (\%) } & \multicolumn{3}{|c|}{ Fecundity } \\
\hline & & \multirow[t]{2}{*}{$3^{\text {rd }}$ larval instar } & \multirow[t]{2}{*}{ Pupae } & \multirow[t]{2}{*}{ adults } & \multirow[t]{2}{*}{ Total } & \multicolumn{2}{|c|}{ Mean No. of eggs/female* } & \multirow[t]{2}{*}{ Deterrent index (\%) } \\
\hline & & & & & & Treatment & Control & \\
\hline Initial & 20.0 & 10.0 & $3 . .3$ & 3.3 & 36.6 & $742^{b}$ & $850^{a}$ & 6.78 \\
\hline 1-day & 10.0 & 6.6 & 3.3 & 3.3 & 23.2 & $774^{b}$ & $875^{a}$ & 6.13 \\
\hline 2 days & 6.6 & 3.3 & 0.0 & 0.0 & 9.9 & $835^{\mathrm{b}}$ & $865^{a}$ & 1.77 \\
\hline 3 days & 6.6 & 3.3 & 0.0 & 0.0 & 9.9 & $842^{a}$ & $855^{\mathrm{a}}$ & 0.77 \\
\hline 4 days & 3.3 & 0.0 & 0.0 & 0.0 & 3.3 & $865^{\text {a }}$ & $865^{a}$ & 0.00 \\
\hline
\end{tabular}

Table (2): Residual effect of confidor $20 \%$ SL on mortality (\%) of the $2^{\text {nd }}$ larval instar and further $3^{\text {rd }}$ larval instar, pupae, adults and fecundity of $\mathrm{Ch}$. carnea (Stephens) in the laboratory.

\begin{tabular}{|c|c|c|c|c|c|c|c|c|}
\hline \multirow{4}{*}{$\begin{array}{c}\text { Days } \\
\text { post application }\end{array}$} & \multirow{4}{*}{$\begin{array}{l}\text { Mortality }(\%) \text { of } \\
\text { the } 2^{\text {nd }} \text { larval } \\
\text { instar }\end{array}$} & \multicolumn{7}{|c|}{ Cumulative effect } \\
\hline & & \multicolumn{4}{|c|}{ Mortality (\%) } & \multicolumn{3}{|c|}{ Fecundity } \\
\hline & & \multirow{2}{*}{$\begin{array}{c}3^{\text {rd }} \text { larval } \\
\text { instar }\end{array}$} & \multirow[t]{2}{*}{ Pupae } & \multirow[t]{2}{*}{ adults } & \multirow[t]{2}{*}{ Total } & \multicolumn{2}{|c|}{ Mean No. of eggs/female* } & \multirow{2}{*}{$\begin{array}{c}\text { Deterrent index } \\
(\%)\end{array}$} \\
\hline & & & & & & Treatment & Control & \\
\hline Initial & 26.7 & 6.7 & 3.3 & 3.3 & 40.0 & $393^{b}$ & $620^{\mathrm{a}}$ & 22.41 \\
\hline 1-day & 16.7 & 6.7 & 3.3 & 0.0 & 26.7 & $417^{b}$ & $630^{a}$ & 20.34 \\
\hline 2 days & 10.0 & 6.7 & 0.0 & 0.0 & 16.7 & $492^{b}$ & $650^{\mathrm{a}}$ & 13.84 \\
\hline 3 days & 6.7 & 3.3 & 0.0 & 0.0 & 10.0 & $546^{\mathrm{b}}$ & $620^{a}$ & 6.35 \\
\hline 4 days & 3.3 & 0.0 & 0.0 & 0.0 & 3.3 & $590^{\mathrm{a}}$ & $600^{a}$ & 0.84 \\
\hline
\end{tabular}

Table (3): Residual effect of aphox $50 \%$ DG on mortality (\%) of the $2^{\text {nd }}$ larval instar and further $3^{\text {rd }}$ larval instar, pupae, adults and fecundity of $\mathrm{Ch}$. carnea (Stephens) in the laboratory.

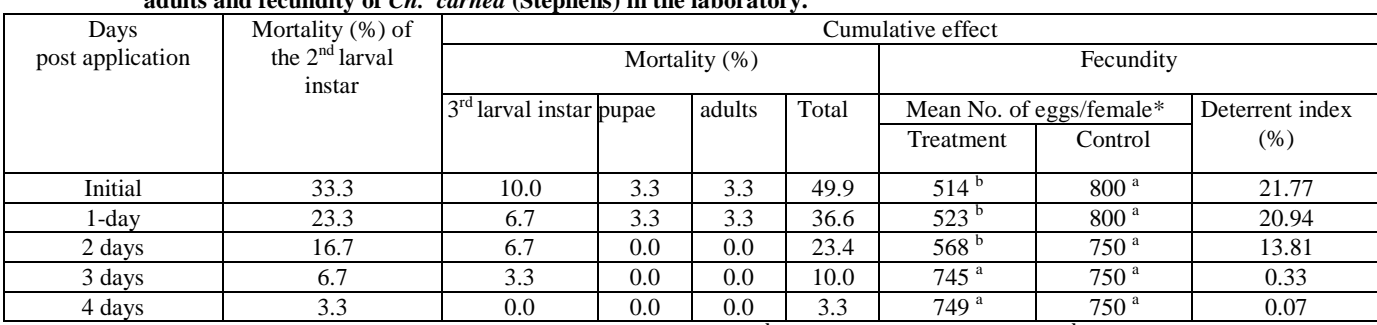

Table (4): Residual effect of trebon $30 \% \mathrm{EC}$ on mortality (\%) of the $2^{\text {nd }}$ larval instar and further $3^{\text {rd }}$ larval instar, pupae,

\begin{tabular}{|c|c|c|c|c|c|c|c|c|}
\hline \multirow{4}{*}{$\begin{array}{c}\text { Days } \\
\text { post } \\
\text { application }\end{array}$} & \multirow{4}{*}{$\begin{array}{l}\text { Mortality (\%) of } \\
\text { the } 2^{\text {nd }} \text { larval } \\
\text { instar }\end{array}$} & \multicolumn{7}{|c|}{ Cumulative effect } \\
\hline & & \multicolumn{4}{|c|}{ Mortality (\%) } & \multicolumn{3}{|c|}{ Fecundity } \\
\hline & & \multirow{2}{*}{$\begin{array}{c}3^{\text {rd }} \text { larval } \\
\text { instar }\end{array}$} & \multirow[t]{2}{*}{ pupae } & \multirow[t]{2}{*}{ adults } & \multirow[t]{2}{*}{ Total } & \multicolumn{2}{|c|}{ Mean No. of eggs/female* } & \multirow{2}{*}{$\begin{array}{c}\text { Deterrent index } \\
(\%)\end{array}$} \\
\hline & & & & & & Treatment & Control & \\
\hline Initial & 30.0 & 13.3 & 3.3 & 3.3 & 49.9 & $412^{\mathrm{b}}$ & $700^{\mathrm{a}}$ & 25.90 \\
\hline 1-day & 23.3 & 10.0 & 3.3 & 3.3 & 39.9 & $435^{b}$ & $700^{a}$ & 23.35 \\
\hline 2 days & 16.7 & 10.0 & 0.0 & 0.0 & 26.7 & $560^{\mathrm{b}}$ & $720^{a}$ & 12.50 \\
\hline 3 days & 10.0 & 6.7 & 0.0 & 0.0 & 16.7 & $616^{\mathrm{b}}$ & $690^{\mathrm{a}}$ & 5.67 \\
\hline 4 days & 0.0 & 0.0 & 0.0 & 0.0 & 0.0 & $680^{a}$ & $700^{a}$ & 1.45 \\
\hline
\end{tabular}

Table (5): Residual effect of vertimec $1.8 \%$ EC on mortality (\%) of the $2^{\text {nd }}$ larval instar and further $3^{\text {rd }}$ larval instar, pupae, adults and fecundity of $\mathrm{Ch}$. carnea (Stephens) in the laboratory.

\begin{tabular}{|c|c|c|c|c|c|c|c|c|}
\hline \multirow{4}{*}{$\begin{array}{c}\text { Days } \\
\text { post application }\end{array}$} & \multirow{4}{*}{$\begin{array}{l}\text { Mortality (\%) of } \\
\text { the } 2^{\text {nd }} \text { larval } \\
\text { instar }\end{array}$} & \multicolumn{7}{|c|}{ Cumulative effect } \\
\hline & & \multicolumn{4}{|c|}{ Mortality (\%) } & \multicolumn{3}{|c|}{ Fecundity } \\
\hline & & \multirow{2}{*}{$\begin{array}{c}3^{\text {rd }} \text { larval } \\
\text { instar }\end{array}$} & \multirow[t]{2}{*}{ pupae } & \multirow[t]{2}{*}{ adults } & \multirow[t]{2}{*}{ Total } & \multicolumn{2}{|c|}{ Mean No. of eggs/female* } & \multirow{2}{*}{$\begin{array}{c}\text { Deterrent index } \\
(\%)\end{array}$} \\
\hline & & & & & & Treatment & Control & \\
\hline Initial & 26.7 & 9.7 & 6.6 & 3.3 & 46.3 & $477^{b}$ & $750^{a}$ & 22.25 \\
\hline 1-day & 13.3 & 6.6 & 3.3 & 3.3 & 26.5 & $496^{b}$ & $700^{a}$ & 17.06 \\
\hline 2 days & 10.0 & 3.3 & 0.0 & 0.0 & 13.3 & $702^{b}$ & $750^{a}$ & 3.31 \\
\hline 3 days & 6.6 & 0.0 & 0.0 & 0.0 & 6.6 & $662^{b}$ & $700^{a}$ & 2.79 \\
\hline 4 days & 3.3 & 0.0 & 0.0 & 0.0 & 3.3 & $727^{\mathrm{a}}$ & $750^{\mathrm{a}}$ & 1.56 \\
\hline
\end{tabular}

Table (6): Residual effect of topas (100) $10 \%$ EC on mortality (\%) of the $2^{\text {nd }}$ larval instar and further $3^{\text {rd }}$ larval instar, pupae, adults and fecundity of Ch. carnea (Stephens) in the laboratory.

\begin{tabular}{|c|c|c|c|c|c|c|c|c|}
\hline \multirow{4}{*}{$\begin{array}{c}\text { Days } \\
\text { post application }\end{array}$} & \multirow{4}{*}{$\begin{array}{l}\text { Mortality (\%) of } \\
\text { the } 2^{\text {nd }} \text { larval } \\
\text { instar }\end{array}$} & \multicolumn{7}{|c|}{ Cumulative effect } \\
\hline & & \multicolumn{4}{|c|}{ Mortality (\%) } & \multicolumn{3}{|c|}{ Fecundity } \\
\hline & & \multirow{2}{*}{$\begin{array}{c}3^{\text {rd }} \text { larval } \\
\text { instar }\end{array}$} & \multirow[t]{2}{*}{ pupae } & \multirow[t]{2}{*}{ adults } & \multirow[t]{2}{*}{ Total } & \multicolumn{2}{|c|}{ Mean No. of eggs/female* } & \multirow{2}{*}{$\begin{array}{l}\text { Deterrent index } \\
(\%)\end{array}$} \\
\hline & & & & & & Treatment & Control & \\
\hline Initial & 16.7 & 10.0 & 3.3 & 0.0 & 30.0 & $500^{b}$ & $760^{a}$ & 20.64 \\
\hline 1-day & 12.7 & 6.6 & 3.3 & 0.0 & 22.6 & $549^{b}$ & $760^{a}$ & 16.12 \\
\hline 2 days & 10.0 & 0.0 & 0.0 & 0.0 & 10.0 & $585^{\mathrm{b}}$ & $750^{a}$ & 12.36 \\
\hline 3 days & 6.7 & 0.0 & 0.0 & 0.0 & 6.7 & $593^{b}$ & $700^{a}$ & 8.28 \\
\hline 4 days & 3.3 & 0.0 & 0.0 & 0.0 & 3.3 & $680^{\mathrm{a}}$ & $700^{a}$ & 1.45 \\
\hline
\end{tabular}

* Means in the same row not followed by the same letter are significantly different $(\mathrm{P}<0.05)$ using Dunce Multiple Range Test 
application. In the fourth day of post application there was no residual effect on the second larval instar in all pesticide treatments. These results confirmed that the persistence of the tested pesticides were shorter in the greenhouse than those in the laboratory test. In general, the toxicity of the chosen pesticides against the second larval instar at initial time in the greenhouse was slightly lower than those in the laboratory test.

Also, the cumulative effect of the chosen pesticides on mortality of developed stages produced from the treated second larval instar of Ch. carnea was evaluated in the greenhouse trials. The percentage mortalities of the third larval instar ranged between 6.6 and $13.3 \%$ at the initial time and then gradually decreased to reach $3.3 \%$ in the second day post application with all tested pesticides except topas $100(0.0)$. The chosen pesticides caused $3.3 \%$ mortality only in the pupa stage at the initial and first day post application except aphoxic, which was the most potent pesticide and gave 10.0, 6.7 and $3.3 \%$ mortality at $0,1^{\text {st }}$ and $2^{\text {nd }}$ day post application, respectively. Bancol, confidor, trebon and topas (100) had no cumulative effect on the adults emergence developed from the treated second larval instar. In contrary, aphox and vertimec were effective against adult's emergence and caused $6.7 \%$ and $3.3 \%$ mortality at the initial time.

The results of total mortality for different stages at initial time of application indicated that aphox was the most toxic one, while topas (100) was the least toxic. The tested pesticides were arranged according to the total mortality percentage at initial time in the following descending order; aphox (53.3\%), confidor $(46.6 \%)$, trebon $(39.9 \%)$, vertimec $(39.9 \%)$, bancol (33.3\%) and topas $(23.3 \%)$. The corresponding values in laboratory experiments were $49.9,40.0$, $49.9, \quad 46.3, \quad 36.6$ and $30.0 \%$, respectively. Accordingly, the total percentage mortality was mostly higher in the laboratory tests than those in the greenhouse trials except in the case of aphox and confidor. It was gradually decreased with time elapsed and reached 3.3\% in bancol, aphox, trebon and topas (100) treatments and 6.7\% using confidor and vertimec at the third day of application. The chosen pesticides had no residual effect on the different stages of Ch. carnea at the fourth day post application. The residual lethal toxicity of the tested pesticides persisted for three days after application in greenhouse trials and four days in the case of laboratory tests.

The results presented in Tables (7-12) show that the treated second larval instar with the chosen pesticides induced adverse effects on the female's fecundity and egg hatching. At the initial time, the deposited eggs per female were drastically decreased from 563.8 for control treatment to 321.2, 245.6 and 320.0 in bancol, confidor and aphox treatments with deterrent indices 27.4, 39.3 and $27.6 \%$, respectively. The same trend was also found using trebon, vertimec and topas (100), which the deposited eggs decreased from 560.7 for control to $265.0,258.5$ and 318.8 with deterrent indices $35.8,36.9$ and $27.5 \%$, respectively. The deposited eggs were significantly decreased up to the second day post application for all tested pesticides with deterrent indices 3.0, 9.6, 15.0, 8.9, 3.9 and $21.4 \%$ for the treatments of bancol, confidor, aphox, trebon, vertimec and topas (100), respectively. All the tested pesticides had no adverse effect on the fecundity of Ch. carnea females in the third and fourth day post application. Data indicated that the adverse effect on the fecundity of $C h$. carnea females using the tested pesticides was shorter in greenhouse trials than those in laboratory tests.

The cumulative effect of the tested pesticides on eggs hatching of Ch. carnea is presented in Tables (7-12). All pesticide treatments are affected the survival of Ch. carnea hatching. The positive relationship between the percentage hatchability and time elapsed was found for all tested pesticides. The candidate pesticides were arranged according to sterility percentage at initial time in the following descending order; confidor $(64.6 \%)$, vertimec $(60.3 \%)$, trebon $(60.2 \%)$, aphox $(53.0 \%)$, bancol $(52.0 \%)$ and topas $(51.4 \%)$. The percentage hatchability increased while the percentage sterility decreased with time elapsed in all treatments of pesticides. Percentage hatchability was increased from the range of $77-82 \%$ at initial time to $90-93 \%$ after four days of pesticides application. There were slightly differences in the percentage hatchability of eggs between pesticide treatments and control after three and four days of application. The percentage sterility decreased from the range of $51.4-64.6 \%$ in pesticide treatments at initial time to $2.2-7.8 \%$ after four days post application. Based on the percentage sterility at the fourth day post application the tested pesticides can be arrange in the following descending order; aphox (7.8\%), vertemic $(4.3 \%)$, topas $(3.9 \%)$, bancol $(3.2 \%)$, confidor (2.2\%) and trebon (2.2\%).

Although in the greenhouse trials the pesticide deposit was on cucumber seedlings instead of pepper seedlings in laboratory tests but the same toxicity trend of the tested pesticides to the second larval instar of Ch. carnea and their developed 
stages in laboratory tests was also found in the greenhouse trials. The toxicity data of the tested pesticides in the greenhouse confirmed the previously results of the laboratory tests, which indicated that four days waiting period is required after application of the chosen pesticides to prevent any effect on the $2^{\text {nd }}$ larval instar (release stage) and their developed stages.

The same trials that were conducted on cucumber seedling in the greenhouse to study the residual effect of chosen pesticides on the second larval instar and their developed stages were also applied with feeding the second larval instar with aphids (Aphis gossypii) instead of Ephestia kuheniella eggs to be identical for field conditions. Although the Aphis gossypii was used for feeding in these trials but the same toxicity trend of tested pesticide residues at the third and fourth day of application was also found. The results in Table (13) indicated that the residues of the tested pesticides had no effect on mortality, fecundity and egg hatchability of Ch. carnea after four days of application. Also, the data confirmed that the preferable time for releasing the second larval instar is four days after application with bancol, confidor, aphox, trebon, vertimec and topas against leaf miners, thrips, aphids, whiteflies, red spider mites and powdery mildew disease, respectively, to avoid any toxic effect on the different stages of Ch. carnea.

\section{DISCUSSION}

Integrated use of natural enemies particularly Ch. carnea for controlling vegetables aphid with different pesticides against other pests appears possible by the use of selective pesticides or the use of reduced concentrations of other pesticides, so that at least one life stage of Ch. carnea will be conserved. In fact, it is difficult and not acceptable reducing the recommended rate of pesticides in controlling different pests in order to decrease their side effects on natural enemies. Accordingly, the unique way in integrated use of natural enemies with different pesticides is by choosing the safer pesticides to these natural enemies especially there are a several recommended pesticides against each pest. The combination of Ch. carnea and selective pesticides opened an unprecedented window of opportunity for an increased impact of biological control on vegetable crops in greenhouses and fields. The negative impact of many agricultural pesticides on biological control agents is well documented (Croft and Brown 1975, Hassan et al., 1985, Croft 1990, Bigler and Waldburger 1994, Elarnaouty and Badawy 1998, Badawy and El- arnaouty 1999, Chen and Liu 2002 and Bueno and Freitas 2004). The integration of biological and chemical control tactics requires a thorough understanding of how pesticide residues affect biological control agents.

Any pesticide applied during the growing season has the potential to disrupt biological control. The chosen insecticides in this study were bancol (bensultap), confidor (imidacloprid), aphox (pirimicarb) and trebon (etofenprox), which are less harmful to Ch. carnea (Badawy et al., 2006). These insecticides belong to the following chemical groups; nereistoxin analogue, neonicotinoid, carbamate and non ester-pyrethroid, respectively. Also, the acaricide vertimec (abamectin) and the fungicide topas 100 (penconazole) used in this study, belong to biopesticide and triazole groups. The results of total mortality for different stages of Ch. carnea at initial time of application in greenhouse trials indicated that aphox was the most toxic one, while topas (100) was the least toxic. The tested pesticides were arranged according to the total mortality percentage at initial time in the following descending order; aphox, confidor, trebon, vertimec, bancol and topas (100), while in the laboratory test were as follows; aphox, trebon, vertimec, confidor, bancol and topas (100), respectively. These results were supported by Croft (1990) who reported that organophosphate, carbamate and synthetic pyrethroid insecticides are generally considered highly toxic to biological control agents due to their broad spectrum activity. With one exception of this finding is the carbamate insecticide pirimicarb, which was less toxic to $C h$. carnea than the other insecticides that belong to the same chemical group according to the observation of Helgesen and Tauber (1974), ElArnaouty and Badawy (1998), Jansen (2000) and Badawy et al., (2006). Also, the data presented here about the candidate pesticides support the observation of Biddinger and Hull 1995, Raguraman and Singh 1999, Smith and Krischik 1999, Elzen et al., 2000, Hill and Foster 2000 and Villanueva-Jimenez et al., 2000 who found that new insecticide chemistry, with novel modes of action, are potentially more selective by having greater impact on the target pest than on natural enemies, thus conserving biological control agents in agricultural environments.

Mass-rearing methods are being developed to produce Ch. carnea for augmentative release which are expected to overcome the problem of low predator abundance. When Ch. carnea is mass released as a biological control agent against 


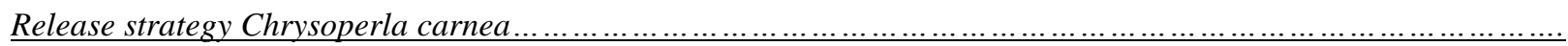

\begin{tabular}{|c|c|c|c|c|c|c|c|c|c|c|c|}
\hline \multirow{3}{*}{$\begin{array}{l}\text { Days after } \\
\text { application }\end{array}$} & \multirow{3}{*}{$\begin{array}{l}\text { Mortality (\%) of } \\
\text { the } 2^{\text {nd }} \text { larval } \\
\text { instar** }\end{array}$} & \multirow{2}{*}{\multicolumn{4}{|c|}{ Mortality (\%) }} & \multirow{2}{*}{\multicolumn{3}{|c|}{$\begin{array}{r}\text { Cumulative effect } \\
\text { Fecundity }\end{array}$}} & \multirow{2}{*}{\multicolumn{3}{|c|}{ Hatchability (\%) }} \\
\hline & & & & & & & & & & & \\
\hline & & $\mathbf{3}^{\text {rd }}$ larval instar & \begin{tabular}{l|l} 
pupae \\
\end{tabular} & adults & Total & \multicolumn{2}{|c|}{ Mean No. of eggs/female* } & $\begin{array}{l}\text { Deterrent index } \\
(\%)\end{array}$ & Treatment & Control & $\begin{array}{c}\text { Sterility } \\
(\%)\end{array}$ \\
\hline Initial & 16.7 & 13.3 & 3.3 & 0.0 & 33.3 & $321.2^{\mathrm{b}}$ & $563.8^{\mathrm{a}}$ & 27.41 & 80 & 95 & 52.03 \\
\hline 1-day & 16.7 & 6.7 & 3.3 & 0.0 & 26.7 & $352.4^{b}$ & $564.6^{\mathrm{a}}$ & 23.14 & 81 & 95 & 46.78 \\
\hline 2 days & 10.0 & 3.3 & 0.0 & 0.0 & 13.3 & $544.0^{b}$ & $577.6^{\mathrm{a}}$ & 3.00 & 85 & 93 & 13.92 \\
\hline 3 days & 3.3 & 0.0 & 0.0 & 0.0 & 3.3 & $570.0^{a}$ & $588.8^{\mathrm{a}}$ & 1.62 & 90 & 95 & 8.29 \\
\hline 4 days & \begin{tabular}{l|l}
0.0 \\
\end{tabular} & \begin{tabular}{|l|l}
0.0 & \\
\end{tabular} & \begin{tabular}{l|l}
0.0 & \\
\end{tabular} & 0.0 & 0.0 & $582.0^{\mathrm{a}}$ & $588.8^{\mathrm{a}}$ & 0.58 & 93 & 95 & 3.24 \\
\hline \multirow{2}{*}{\multicolumn{12}{|c|}{$\begin{array}{l}\text { S on mortality (\%) of the } 2^{n d} \text { larval instar and further } 3^{r d} \text { larval instar, pupae, adults, fecundity a } \\
\text { Cumulative effect }\end{array}$}} \\
\hline & & & & & & & & & & & \\
\hline \multirow{3}{*}{ application } & \multirow{3}{*}{$\begin{array}{l}\text { the } 2^{\text {nd }} \text { larval } \\
\text { instar** }\end{array}$} & \multicolumn{4}{|c|}{ Mortality (\%) } & \multicolumn{3}{|c|}{ Fecundity } & \multicolumn{3}{|c|}{ Hatchability (\%) } \\
\hline & & \multirow[t]{2}{*}{$\mathbf{3}^{\text {rd }}$ larval instar } & \multirow[t]{2}{*}{ pupae } & \multirow[t]{2}{*}{ adults } & \multirow[t]{2}{*}{ Total } & Mean No. 0 & s/female* & Deterrent index & Treatment & Control & Sterility \\
\hline & & & & & & Treatment & Control & $(\%)$ & & & $(\%)$ \\
\hline Initial & 30.0 & 13.3 & 3.3 & 0.0 & 46.6 & $245.6^{b}$ & $563.8^{\mathrm{a}}$ & 39.31 & 78 & 96 & 64.61 \\
\hline 1-day & 16.6 & 6.7 & 3.3 & 0.0 & 26.6 & $362.0^{b}$ & $564.6^{a}$ & 21.87 & 83 & 95 & 43.98 \\
\hline 2 days & 10.0 & 3.3 & 0.0 & 0.0 & 13.3 & $476.6^{b}$ & $577.6^{\mathrm{a}}$ & 9.58 & 85 & 95 & 26.17 \\
\hline 3 days & 6.7 & 0.0 & 0.0 & 0.0 & 6.7 & $588.8^{a}$ & $\mathbf{5 8 8 . 8}^{\mathrm{a}}$ & 0.00 & 90 & 93 & 3.23 \\
\hline 4 days & 0.0 & $\begin{array}{l}0.0 \\
0.0\end{array}$ & 0.0 & 0.0 & 0.0 & $588.2^{\mathrm{a}}$ & $588.8^{a}$ & 0.05 & 93 & 95 & 2.21 \\
\hline Table (9): Residu & 1 effect of aphox 50\% DC & G on mortality (\%) of & the $2^{\text {nd }}$ lart & val instar an & nd further $3^{\text {rd }} \mathbf{l}$ & rval instar, pupae & ts, fecundity an & atchability of $\mathrm{Ch}$. $\mathrm{carn}$ & nea (Stephens) in & the greenhous & \\
\hline Days after & Mortality (\%) & & & & & & mulative effect & & & & \\
\hline application & the $2^{\text {nd } d}$ larval & & Mortality & $y(\%)$ & & & Fecundi & & & Iatchability & \\
\hline & instar** & $\mathbf{3}^{\text {rd }}$ larval insta & $\begin{array}{l}\mathbf{r} \text { pupa } \\
\end{array}$ & e adults & Total & Mean N & eggs/female* & Deterrent index & Treatment & \begin{tabular}{|c|c|} 
& Control
\end{tabular} & Sterility \\
\hline & & & & & & Treatment & Control & $(\%)$ & & & $(\%)$ \\
\hline Initial & 23.3 & 13.3 & 10.0 & 6.7 & 53.3 & $320.0^{\mathrm{b}}$ & $563.8^{\mathrm{a}}$ & 27.59 & 77 & 93 & 53.01 \\
\hline 1-day & 16.7 & 6.7 & 6.7 & 0.0 & 30.1 & $324.6^{b}$ & $564.6^{a}$ & 26.99 & 82 & 92 & 48.76 \\
\hline 2 days & 13.3 & 3.3 & 3.3 & 0.0 & 19.9 & $427.2^{b}$ & $577.7^{\mathrm{a}}$ & 14.97 & 85 & 93 & 32.41 \\
\hline 3 days & 3.3 & 0.0 & 0.0 & 0.0 & 3.3 & $588.8^{a}$ & $588.8^{\mathrm{a}}$ & 0.00 & 90 & 95 & 5.26 \\
\hline 4 days & \begin{tabular}{l|l} 
& 0.0 \\
\end{tabular} & \begin{tabular}{|c|c|} 
& $\mathbf{0 . 0}$
\end{tabular} & \begin{tabular}{|l|l|}
0.0 \\
\end{tabular} & \begin{tabular}{|l|}
0.0 \\
\end{tabular} & \begin{tabular}{|l|l|} 
& 0.0 \\
\end{tabular} & \begin{tabular}{|l|l} 
& $573.3^{\mathrm{a}}$ \\
\end{tabular} & $\mathbf{5 8 8 . 8}^{\mathrm{a}}$ & \begin{tabular}{|l|l|} 
& 1.34 \\
\end{tabular} & \begin{tabular}{l|l|} 
& 90 \\
\end{tabular} & \begin{tabular}{|l|l|} 
& 95 \\
\end{tabular} & 7.77 \\
\hline Table (10): Resid & al effect of trebon $30 \%$ & EC on mortality (\%) & f the $2^{n d}$ la & Irval instar a & and further $3^{r c}$ & arval instar, pupa & ults, fecundity a & hatchability of $\mathrm{Ch} . \mathrm{ca}$ & rnea (Stephens) in & the greenhou & \\
\hline Days after & Mortality (\%) of & & & & & & lative effect & & & & \\
\hline application & the $2^{\text {nd }}$ larval & & ortality $(c$ & & & & Fecundity & & Hat & chability (\% & \\
\hline & instar** & $\mathbf{3}^{\text {rd }}$ larval instar & pupae & adults & Total & Mean No. & ggs/female* & Deterrent index & Treatment & Control & Sterility \\
\hline & & & & & & Treatment & Control & $(\%)$ & & & $(\%)$ \\
\hline Initial & 30.0 & 6.6 & 3.3 & 0.0 & 39.9 & $265.0^{b}$ & $560.7^{a}$ & 35.81 & 80 & 95 & 60.20 \\
\hline 1-day & 16.7 & 10 & 3.3 & 0.0 & 30.0 & $402.5^{b}$ & $563.4^{a}$ & 16.66 & 81 & 95 & 39.09 \\
\hline 2 days & 10 & 3.3 & 0.0 & 0.0 & 13.3 & $492.8^{b}$ & $588.8^{a}$ & 8.88 & 85 & 93 & 23.50 \\
\hline 3 days & 3.3 & 0.0 & 0.0 & 0.0 & 3.3 & $595.6^{\mathrm{a}}$ & $596.5^{\mathrm{a}}$ & 0.08 & 90 & 95 & 5.41 \\
\hline 4 days & 0.0 & 0.0 & 0.0 & 0.0 & 0.0 & $596.0^{\mathrm{a}}$ & $596.5^{\mathrm{a}}$ & 0.04 & 93 & 95 & 2.19 \\
\hline
\end{tabular}




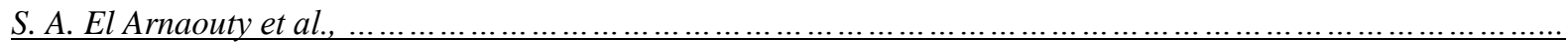

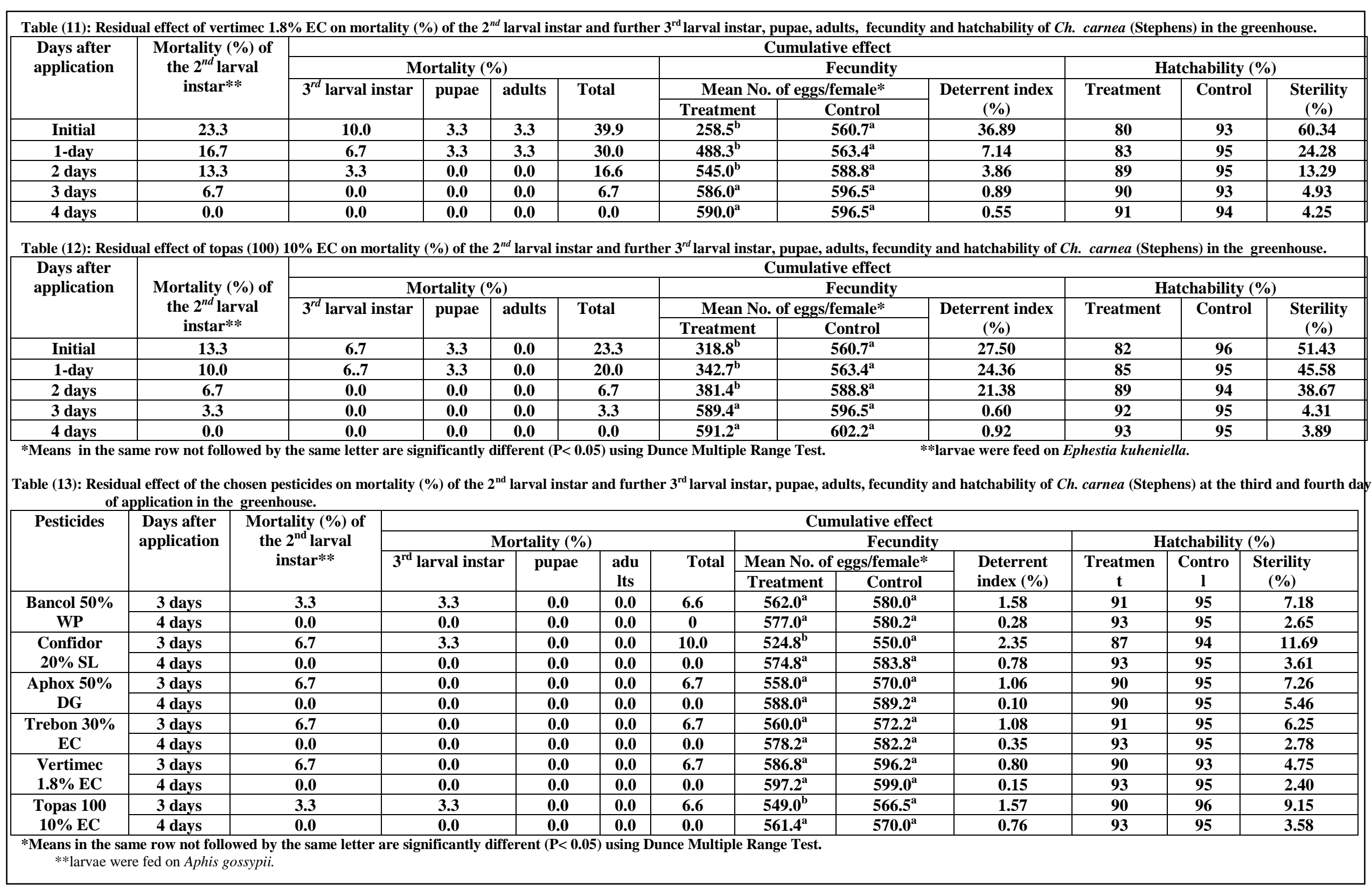


aphids, its success may depend on its tolerance to these pesticides targeted at non-host pests and also the release timing after application with pesticides. This study aimed to evaluate the residual effect of the chosen pesticides in order to appoint the release time of the second larval instar after the application of these pesticides at their recommended rates. The present data showed that the total percent mortality in the different stages of Ch. carnea was mostly lower in the greenhouse trials than those in the laboratory tests except in the case of aphox and confidor. Also, the persistence of the tested pesticides was slightly shorter in greenhouse than in laboratory test. The residual lethal toxicity of the tested pesticides persisted for three days after application in greenhouse trials and four days in the case of laboratory tests. It may be due to the differences in weather conditions between the laboratory and the greenhouse. This finding agree with Croft (1990) who stated that the persistence of pesticides residues depends largely on the product formulation, the applied rate, weather conditions and the type of surface on which a pesticide is applied. Also, Verkerk and Wright (1996) reported that number of factors, such as photostability, translaminar uptake, and leaf nutritional status will affect residual efficacy. The intrinsic efficacy (the oral ingestion toxicity) of the tested pesticides did not occur by the second larval instar of Ch. carnea. This allows the conclusion that there were no significant differences in the toxicity of the tested insecticides on pepper or cucumber seedlings against the second larval instar and we cannot explain the slight differences responding the plant specific properties as described by Verkerk and Wright (1996).

Results presented here show that the treated second larval instar with the chosen pesticides induced adverse effects on the female's fecundity and egg hatching. The deposited eggs were significantly decreased up to the second day post application for all tested pesticides in the greenhouse. All pesticide treatments affected the survival of Ch. carnea hatching. The percent hatchability increased, while the percent sterility decreased with time elapsed in all treatments of pesticides. There were slight differences in the percentage hatchability of eggs between pesticide treatments and control after three and four days of application. These results were confirmed by Huerta et al. (2003) who found that the residues of natural pyrethrin and imidacloprid had a strong effect on survival and egg hatchability of $C h$. carnea. It was also observed in this study that some treated larvae of the $2^{\text {nd }}$ instar had developed to $3^{\text {rd }}$ instar, but completely failed to produce silk for cocooning as a result, these larvae could not successfully pupate and died. Among the larvae that succeed in spinning a complete cocoon, some died within it without reaching the adult stage. The same finding was obtained by Shour and Crowder (1980) and Chen and Liu (2002).

Although there are differences in the mode of effect for the tested pesticides, which bancol, and trebon are contacts, while aphox, confidor and topas (100) are systemic in addition to vertimec which has limited plant systemic activity but there are no great differences in their efficacy against the $2^{\text {nd }}$ larval instar of Ch. carnea through all exposure periods were found. These results can be explained from the study of Buchholz and Nauen (2001) who reported that successful pest control by foliar application is not simply related to systemic behaviour alone, but it is much more a combination of systemic and contact properties depending on physico-chemical characteristic of the active ingredient, the plant species (e.g., different barrier properties of cuticles), metabolism and the functional morphology of the pest species considered (e.g. mobile or quiescent stages).

In some pest management systems pesticides that have been touted as selective show negative impacts on beneficial species. A better understanding of how insecticides residue impact selected predators is necessary when developing a pest management system that strives to conserve biological control agents. The efficacy results of pesticides residue in the greenhouse indicated that four days waiting period is required after the application of the chosen pesticides; bancol, confidor, aphox, trebon, vertimec and topas (100) to prevent any effect on the release stage $\left(2^{\text {nd }}\right.$ larval instar) and their developed stages. Also, Deole et al., (2000) found that the toxicity of monocrotophos and fenvalerate to Ch. carnea larvae persisted for two days, whereas chlorpyrifos was toxic for up to five days. On the other hand, the residual effect of the insecticides; clothianidin, dinotefuran, pyridaben, pymetrozine and etofenprox on whitefly adults on tomato seedlings was studied by Barakat et al., (2005). They found that etofenprox caused complete mortality of whitefly adults at the first $48 \mathrm{~h}$. and its residual effect reached the minimum value $(27 \%)$ at the eighth day of application. Also, the toxic effect of clothianidin on whitefly adults was more persistent than the other tested insecticides, while etofenprox had least persistence. These results confirmed the finding of Villanueva-Jimenez et al., (2000) who 
reported that new insecticides have greater impact on the target pest than on natural enemies.

There is low literature about the side effects of pesticides residue on the different stages of $C h$. carnea. Data presented here can be used as a rough guide to the relative influence of pesticides residue on Ch. carnea when each of the tested pesticides is sprayed on vegetable crops at the recommended rate. Therefore, we need more information concerning the residual activity of chemicals against predators. Such information would enable scheduling the safe release of natural enemies for augmentation. Collectively, these data have considerable implication for growers who are selecting insecticides for the use in an integrated pest management program where Ch. carnea is present. Also, these results suggest that the chosen pesticides; bancol, confidor, aphox, trebon, vertimec and topas (100) are less harmful, have short residual activity to $C h$. carnea than to the pests and hence favor natural control by this predator.

\section{REFERENCES}

Abbott W.S. (1925). A method of computing effectiveness of an insecticide. J. Econ. Entomol. 18: 265-270.

Badawy H.M.A. and El-Arnaouty S.A. (1999). Direct and indirect effects of some insecticides on Chrysoperla carnea Stephens (Neuroptera: Chrysopidae). J. of Neuropterology. 2: 67-74.

Badawy H.M.A., El-Arnaouty S.A., El Gantiry A.M. and Gaber N.M. (2006). Toxicity of recommended pesticides against several vegetable pests to different populations of Chrysoperla carnea (Stephens) in the laboratory. Bull. Fac. Agric., Cairo Univ., 57(3): 549-570.

Balasubramani V. and Swamiappan M. (1994). Development and feeding potential of the green lacewing, Chrysoperla carnea (Stephens). (Neuroptera: Chrysopidae) on different insect pests of cotton. Anzeiger-fuerschadling-skunde-pflanzenschutz-ummeitschutz. 8: 165-167.

Barakat A.A., Badawy H. M.A., El-Mahy S.A. and Ibrahim E. S. (2005). Toxicological studies on new insecticides against piercing sucking insects. Recent Technologies In Agriculture, the $3^{\text {rd }}$ conference 14-16 Nov. 2005. Faculty of Agriculture- Cairo University.

Bellows T.S. and Morse J.G. (1993). Toxicity of pesticides used in citrus to Aphytis melinus (Debach) (Hymenoptera: Aphelinidae) and
Rhizobius lophanthae (Blaisd) (Coleoptera: Coccinellidae). Can. Entomol. 125: 987-994.

Bellows T.S., Morse J.G. and Gaston L.K. (1993). Residual toxicity of pesticides used for Lepidoptera insect control on citrus to Aphytis melinus (Debach) (Hymenoptera: Aphelinidae). Can. Entomol. 125: 955-1001.

Biddinger D.J. and Hull L.A. (1995). Effects of several types of insecticides on the mite predator Stethorus punctum (Coleoptera: Coccinellidae) including insect growth regulators and abamectin. J. Econ. Entomol. 88. 358-366.

Bigler F. and Waldburger M. (1994). Effect of pesticides on Chrysoperla carnea Stephens. (Neuroptera: Chrysopidae) in the laboratory and semi field. J. Appl. Entomol. 17: 55-59.

Buchholz A. and Nauen R. (2001). Translocation and translaminar bioavailability of two neonicotinoid insecticides after foliar application to cabbage and cotton. Pest Management Science, 58: 10-16.

Bueno A. F. and Freitas S. (2004). Effect of the insecticides abamectin and lufenuron on eggs and larvae of Chrysoperla externa under laboratory conditions. Biocontrol 49(3):277283.

Castane C., Arino J. and Arno J. (1996). Toxicity of some insecticides and acaricides to the predatory bug Dicyphus tamaninii (Heteroptera: Miridae). Entomophaga 41: 211216.

Chen T.Y. and Liu T.X. (2002). Susceptibility of immature stages of Chrysoperla rufilabris (Neuroptera: Chrysopidae) to Pyriproxyfen, a juvenile hormone analog. J. Appl. Entomol. 126: $125-129$.

Croft B.A. (1990). Arthropod biological control agents and pesticides. Wiley, New York.

Croft B.A. and Brown A.W.A. (1975). Response of arthropod natural enemies to insecticides. Ann. Rev. Entomol. 20: 285-335.

Deole S.A., Bodhade S.N., Mahajan L.B. and Deotale V.Y. (2000). Residual toxicity of some pesticides used in cotton pest management against a Chrysopid (Ch. carnea). J. of Soil and Crop 10(2): 279-281.

El-Arnaouty S.A. (2001). Technical improvements in mass rearing of Ephestia kuehniella (Zeller) (Lepidoptera: Pyralidae) as a substitution prey for a cost- effective production of Chrysoperla carnea (Stephens). Integrated Pest Management Proceedings of the $1^{\text {st }}$ Congress 22-23 April 2001. Faculty of Agriculture-Cairo University. 
El-Arnaouty S.A. and Badawy H.M.A. (1998) Biological effects of some insecticides on immature stages of Chrysoperla carnea Stephens Sensu lato (Neuroptera: Chrysopidae). Proceeding of the $1^{\text {st }}$ Regional Symposium for Applied Biological Control in Mediterranean Countries Cairo, Egypt, October 81-86.

El-Gantiry A.M., Abou-Setta M.M. and Moussa S.F.M. (1999). Certain biological studies on Aphis craccivora and Schizaphis graminum (Homoptera: Aphididae) under different constant temperatures. J. Egypt. Ger. Soc. Zool., 30: 123-132.

Elzen G.W. (2001). Lethal and sublethal effects of insecticide residues on Orius insidiosus (Hemiptera: Anthocoridae) and Geocoris punctipes (Hemiptera: Lygaeidae). J. of Econ. Entomol. 94(1): 55-59.

Elzen G.W., Maldonado S.N. and Rojas M.G. (2000). Lethal and sublethal effects of selected insecticides and an insect growth regulator on the boll weevil (Coleoptera: Curculionidae) ectoparasitoid Catolaccus grandis (Hymenoptera: Pteromalidae). J. Econ. Entomol. 93: 300-303.

Frisbie R.E., El-Zik K.M. and Wilson L.T. (1989). Integrated pest management systems and cotton production. Wiley, New York.

Grundy P.R., Maelzer D., Collins P.J. and Hassan E. (2000). Potential for integrating eleven agricultural insecticides with the predator bug Pristhesancus plagipennis (Hemiptera: Reduviidae). J. Econ. Entomol. 93(3): 581589.

Hassan S.A., Klinghauf F. and Shanin F. (1985). Role of Chrysopa carnea as an aphid predator on suger beet and the effect of pesticides. Zeitschrift fuer angewandte Entomologie, 100: 163-174.

Helgesen R.G. and Tauber M.J. (1974). Pirimicarb an aphicide non-toxic to three entomophagous arthropods. Environ. Entomol. 3: 99-101.

Hill T.A. and Foster R.E. (2000). Effect of insecticides on the diamondback moth (Lepidoptera: Plutellidae) and its parasitoid Diadegma insulare (Hymenoptera: Ichneumonidae). J. Econ. Entomol. 93: 763768.

Hydron S.B. and WhiteComb W.H. (1979). Effects of larval diet on Chrysopa rufilabris. Fla. Entomol. 62: 293-298.
Huerta A., Medina P., Castanera P and Vinuela E. (2003). Residual effects of some modern pesticides on Chrysoperla carnea (Stephens) adults under laboratory conditions. BulletinOILB/ SROP. 26(10): 165-170.

Jansen J.P. (2000). A three year field study on the short term effects of insecticides used in control cereal aphids on plant dwelling aphid predators in winter wheat. Pest - Management Science 56(6): 533-539.

Lundgren L. (1975): Natural plant chemicals acting as oviposition deterrents on cabbage butterflies (Pieris brassicae L., P. rapae L. and Pieris napi L.). Zool. Sci. 253-258.

Morrison R.K. (1985). Chrysopa carnea, PP. 419426. in P. Singh and R. F. Moore [eds.], Handbook of insect rearing, Vol. I. Elsevier, Amsterdam.

Raguraman S. and Singh R.P. (1999). Biological effects of neem (Azadirachta in dica) seed oil on an egg parasitoid, Trichogramma chilonis. J. Econ. Entomol. 92: 1274-1280.

SAS Institule (1985). SAS user,s guide: statistics. SAS Institute, Cary, N. C.

Shour M.H. and Crowder L.A. (1980). Effect of pyrethroid insecticides on the common green lacewing. J. Econ. Entomol. 73: 306-309.

Smith S.F. and Krischik V.A. (1999). Effects of systemic imidacloprid on Coleomegilla maculate (Coleoptera: Coccinellidae). Environ. Entomol. 28: 1189-1195.

Tappozada A., Abdallah S. and El-Defrawi E. (1966). Chemosterilization of larvae and adults of the Egyptian cotton leafworm Prodenia litura by apholate, metepa and tepa. J. Econ. Entomol., 59: Zool. Fenn., 12: 275-279.

Verkerk R.H.J. and Wright D.J. (1996). Effects of interactions between host plants and selective insecticides on larvae of Plutella xylostella (Lepidoptera: Yponomeutidae) in the laboratory. Pesticides Science 46: 171-181.

Villanueva-Jimenez J., Hoy M.A. and Davis F. S. (2000). Field evaluation of integrated pest management compatible pesticides for the citrus leafminer Phyllocnistis citrella (Lepidoptera: Gracillariidae) and its parasitoid Ageniaspis citricola (Hymenoptera: Encyrtidae). J. Econ. Entomol. 93: 357-367

Weichel L and Nauen R. (2003). Uptake, translocation and bioavailability of imidacloprid in several hop varieties. Pest manag. Sci., 60: 440-446. 
استراتيجية إطلاق المفترس كريزوبيرلا كارنيا المستخدم لمكافحة المن ضمن منظومة الادارة المتكاملة للآفات

سيد أشرف الأرناؤوطي ، هاني محمود عاثور بدوي ، عزيزة محمد الجنتيري* ، نيفين محمود جابر*

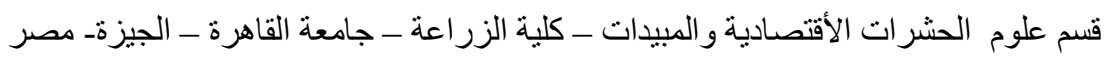

* معهد بحوث وقاية النباتات - مركز البحوث الزراتية الزية ـ الجيزة

\section{ملخص}

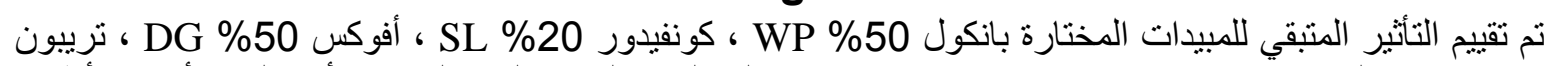

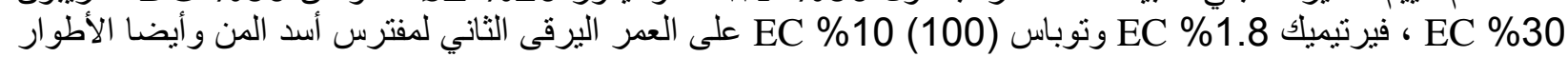

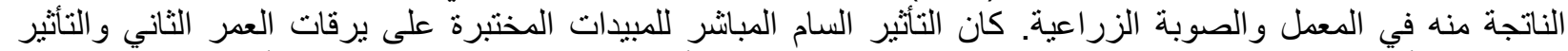

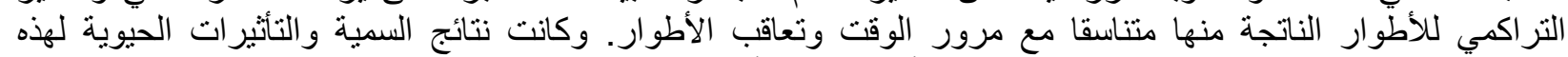

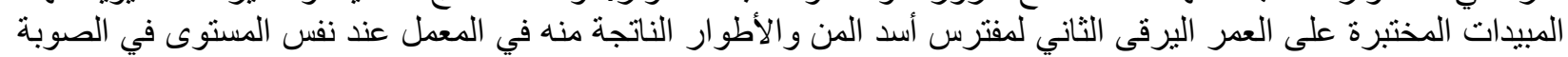

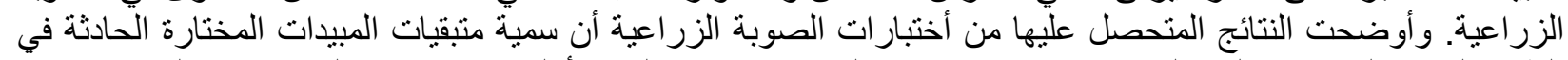

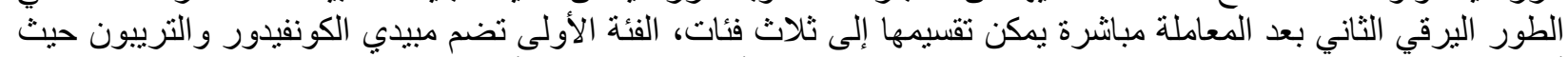

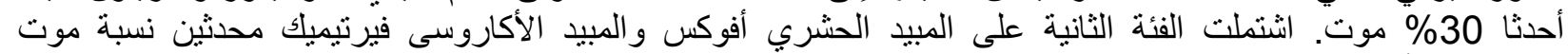

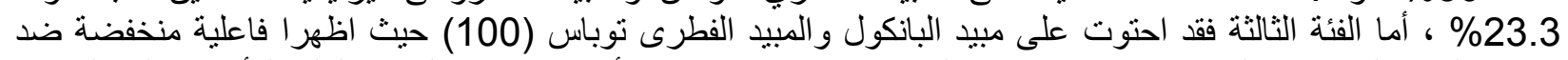

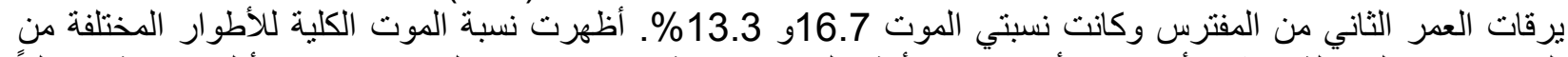

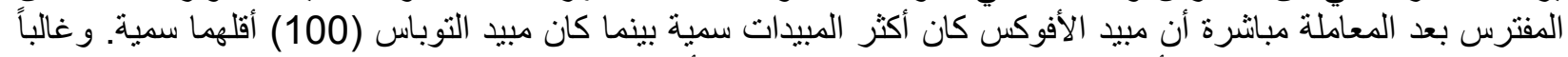

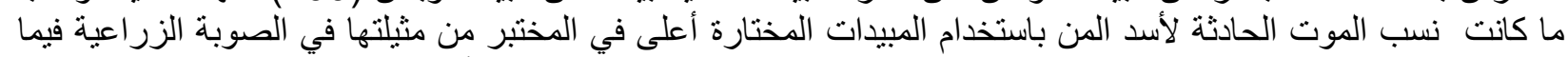

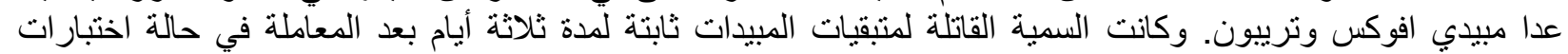

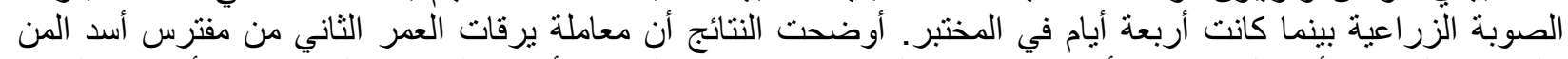

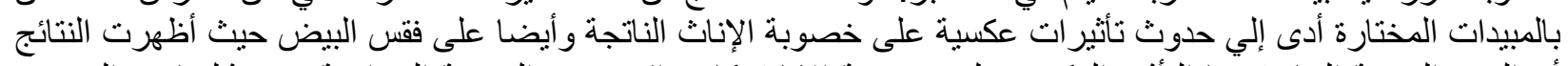

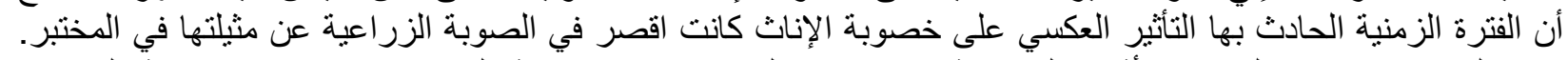

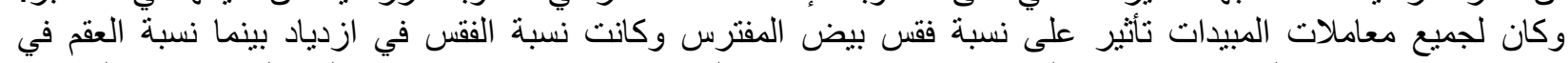

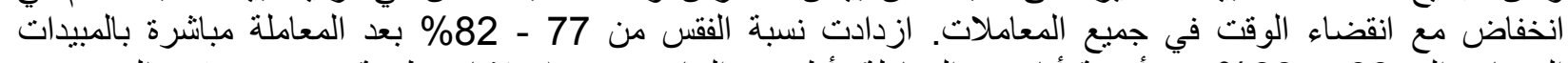

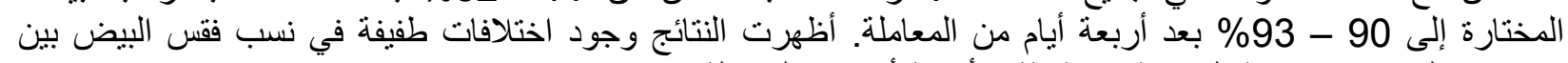

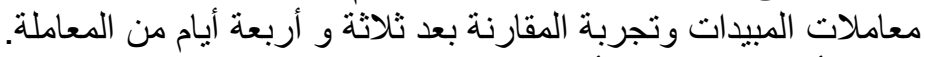

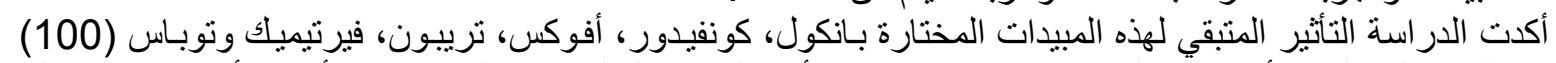

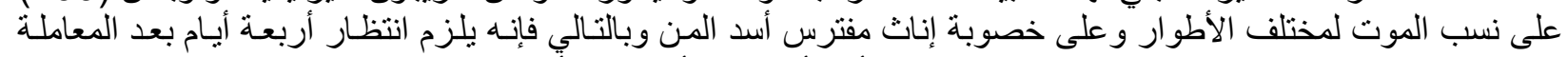

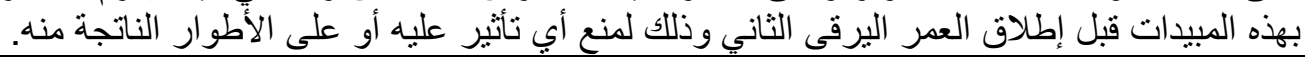

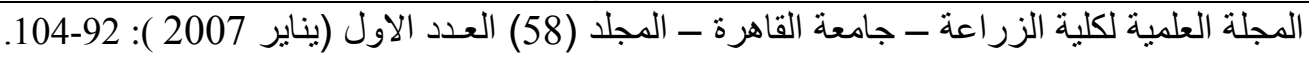

